\title{
Removal of Small-Molecular Byproducts from Crude Fructo-Oligosaccharide Preparations by Fermentation Using the Endospore-Forming Probiotic Bacillus coagulans
}

\author{
Rong Fan ${ }^{1}{ }^{(0}$, Jan P. Burghardt ${ }^{1}\left(\mathbb{D}\right.$, Tao Xiong ${ }^{2}$ and Peter Czermak ${ }^{1,3, *} \mathbb{C}$ \\ 1 Institute of Bioprocess Engineering and Membrane Technology, University of Applied Sciences Mittelhessen, \\ 35390 Giessen, Germany; rong.fan@1se.thm.de (R.F.); jan.burghardt@lse.thm.de (J.P.B.) \\ 2 State Key Laboratory of Food Science and Technology, Nanchang University, Nanchang 330047, China; \\ xiongtao0907@163.com \\ 3 Fraunhofer Institute for Molecular Biology and Applied Ecology (IME), Project Group Bioresources, \\ Heinrich-Buff-Ring 26, 35392 Giessen, Germany \\ * Correspondence: peter.czermak@lse.thm.de; Tel.: +49-641-309-2551; Fax: +49-641-309-2553
}

Received: 13 October 2019; Accepted: 3 January 2020; Published: 7 January 2020

\begin{abstract}
Short-chain prebiotic fructo-oligosaccharides (FOS) produced by enzymatic conversion from sucrose often contains high concentration of monosaccharides as byproducts. In addition to conventional physical/chemical purification processes, microbial treatment is an alternative method to remove these byproducts. We used Bacillus coagulans to reduce the abundance of byproducts during the enzymatic production of FOS. It is a promising probiotic because this thermophilic and spore-forming bacterium remains viable and stable during food processing and storage. B. coagulans also produces lactic acid during the carbohydrate metabolism and is used industrially to produce lactic acid for medical and food/feed applications. We aimed to establish an evaluation system to screen different strains of B. coagulans for their performance and selected B. coagulans Thorne for the treatment of crude FOS due to its high growth rate, high sporulation rate, and low nutrient requirements. B. coagulans preferentially utilized monosaccharides over other sugar components of the FOS mixture. Glucose and fructose were completely consumed during the fermentation but $85 \%(w / w)$ of the total FOS remained. At the end of the fermentation, the total viable cell count of $B$. coagulans Thorne was $9.9 \times 10^{8} \mathrm{cfu} \cdot \mathrm{mL}^{-1}$ and the maximum endospore count was $2.42 \times 10^{4} \mathrm{cfu} \cdot \mathrm{mL}^{-1}$.
\end{abstract}

Keywords: oligosaccharide; prebiotic; sugar metabolism; sporulation; FOS purification; synbiotic

\section{Introduction}

Fructo-oligosaccharides (FOS) are oligosaccharides comprising a sucrose molecule extended by a small number of fructose residues. The D-Fructose residues link by $\beta(2 \rightarrow 1)$ glycosidic bonds, connecting a terminal D-glucose group via $\alpha(1 \rightarrow 2)$ linkage. The general formula is $\mathrm{GF}_{\mathrm{n}}$ and specific examples include 1-kestose $\left(\mathrm{GF}_{2}\right)$, nystose $\left(\mathrm{GF}_{3}\right)$, and 1F-fructofuranosylnystose $\left(\mathrm{GF}_{4}\right)$. The prebiotic activity of FOS has been established in many animal studies and clinical trials, demonstrating their beneficial effects on the immune system, resistance to infection, mineral absorption, and the maintenance of low serum lipid and cholesterol levels [1-3]. They also inhibit pathogens by stimulating certain probiotic gastrointestinal bacteria [4-6]. Furthermore, FOS are comparable in sweetness to sucrose but are only digested to a limited degree by enzymes in the upper part of the gastrointestinal tract $[7,8]$. Therefore, $<10 \%$ of ingested FOS are absorbed in the small intestine $[7,9]$ and they consequently provide very little energy $\left(8.4-9.2 \mathrm{~kJ} \cdot \mathrm{g}^{-1}\right)$ [10]. Accordingly, FOS are used in the food industry as sweeteners 
and prebiotics to reduce the risk of dental caries, obesity, diabetes, diarrhea, hyperlipidemia, and inflammation [11-14].

FOS are storage carbohydrates that occur naturally in many higher plants, including asparagus, sugar beet, garlic, chicory, onion, and banana [11,14]. Although the FOS content of some species is high (e.g., 10-20\% dry weight in chicory and Jerusalem artichoke), most natural sources contain only low levels of these molecules, typically $0.3-6 \%$ dry weight [15]. This means it is uneconomical to extract FOS from natural sources, the availability of which is in any case dependent on the season. The biosynthesis of FOS can be achieved by the hydrolysis of inulin or the transfructosylation of sucrose using fructosyltransferases (FTases) [11,16]. These enzymes transfer the fructose moiety from one molecule of sucrose to another to form the trisaccharide 1-kestose and a free glucose. The chain can be extended with additional fructose units in an analogous manner $[16,17]$. The use of FTases is preferable to the hydrolysis of long-chain inulin because random hydrolysis produces a complex mixture of oligosaccharides with different chain lengths, whereas the activity of FTases can be controlled more precisely $[11,18]$. Pectinex Ultra SP-L is a multi-functional enzyme preparation, which contains pectinase, $\beta$-galactosidase, cellulase, and fructosyl-transferase activities [19]. The fructosyl-transferase in Pectinex Ultra SP-L provides a high fructosyl-transfer activity with a negligible hydrolytic activity when the substrate concentration is properly chosen [20]. Therefore, Pectinex Ultra SP-L has also widely used to produce short chain FOS in addition to the application in fruit juicy processing [16,21]. In this study, we used this enzyme preparation to produce crude FOS from pure sucrose.

The synthesis of FOS using FTases typically involves an initial high concentration of sucrose to promote efficient transfructosylation $[17,22]$. However, the reaction gradually slows down until an equilibrium is established between the substrate (sucrose), products (FOS), and byproducts (glucose and fructose) such that the crude FOS preparation contains large amounts of residual sucrose and the released monosaccharides [22,23]. This increases the plasma glucose level after absorption, an effect often quantitatively described in nutrition science using the glycemic index (GI) [24]. Monosaccharides and disaccharides have high GI values because they are easily absorbed, and high-GI diets increase the risk of metabolic disorders such as diabetes [25]. It is therefore necessary to remove monosaccharides and disaccharides from the crude FOS preparation to reduce the GI, and this can be achieved by physical and chemical processes such as ion exchange chromatography [26,27], ultra/nanofiltration [28,29], and adsorption to activated charcoal [30]. However, these measures are expensive and/or inefficient. The bioconversion of glucose using enzymes or microorganisms is another promising alternative. For example, glucose oxidase has been used to convert the glucose into gluconic acid and hydrogen peroxide [31,32], whereas the use of glucose isomerase to convert glucose into fructose was not effective [33,34]. The microbial treatment of crude FOS preparations has also been considered, using species such as Saccharomyces cerevisiae and Kluyveromyces lactis, which prefer monosaccharides and disaccharides as carbon sources and convert them into ethanol and carbon dioxide, but the ethanol then needs to be removed $[23,35]$. It would be more efficient to convert the unwanted monosaccharides and disaccharides directly into valuable co-products using more suitable microorganisms.

In this study, we selected probiotic Bacillus coagulans (formerly Lactobacillus sporogenes [36]), a facultative anaerobic spore-forming bacterium that converts monosaccharides and disaccharides into lactic acid under anaerobic conditions. According to the definition by Food and Agricultural Organization of the United Nations, and World Health Organization, probiotics refer to live microorganisms that, when in adequate numbers, confer a health benefit on the host $[37,38]$, such as preventing the growth of pathogens, reducing serum lipid levels, and modulating the immune response $[6,12,39,40]$. B. coagulans is a competitive probiotic species because its spore-forming ability allows it to remain viable in the gastrointestinal tract despite the $\mathrm{pH}$ extremes and the presence of digestive enzymes. Many B. coagulans strains have been isolated from diverse sources [41-43]. They differ in terms of growth (biomass accumulation) rate, lactic acid conversion, sporulation, and nutrient requirements, thus it is challenging to select the most appropriate strain for a given industrial process. For example, strains with a high conversion rate and lactate tolerance are needed for lactic acid 
production [43], whereas strains used as probiotics require a high growth rate and a high sporulation rate [42]. Here, we established an evaluation system based on several process parameters to select a candidate from among four model strains of $B$. coagulans that would be suitable for the treatment of crude FOS preparations, and confirmed the suitability of the selected strain for the reduction of monosaccharides and disaccharides in the crude FOS mixture.

\section{Materials and Methods}

\subsection{FOS Synthesis}

The commercial enzyme preparation Pectinex Ultra SP-L (Novozyme A/S, Bagsværd, Denmark) was used for the enzymatic production of FOS, with $600 \mathrm{~g} \cdot \mathrm{L}^{-1}$ sucrose as the substrate buffered with $0.1 \mathrm{M}$ potassium phosphate ( $\mathrm{pH}$ 5.5). The reaction was initiated by mixing the enzyme and substrate solutions at a 1:9 (v:v) ratio. A 100-mL enzyme solution and $900 \mathrm{~mL}$ sucrose were used for each batch of production. The mixture was incubated at $55^{\circ} \mathrm{C}$ on a heating plate stirring at $200 \mathrm{rpm}$. The reaction was terminated by thermal enzyme deactivation at $80^{\circ} \mathrm{C}$ for $20 \mathrm{~min}$.

\subsection{Microorganisms}

Four model strains of B. coagulans were used in this study. B. coagulans DSM 1 and DSM 2312 were purchased from the German Collection of Microorganisms and Cell Cultures (Deutsche Sammlung von Mikroorganismen und Zellkulturen GmbH (DSMZ), Braunschweig, Germany). B. coagulans Thorne was purchased from THORNE Research, Inc. (Summerville, SC, USA; Lot No. 14.06820), which contains high dose of endospores in the formulation of vegetarian capsule [44]. B. coagulans PS5 was kindly supplied by ThyssenKrupp Industrial Solutions AG, Process Technologies (Bad Soden, Germany).

\subsection{Culture Media}

Two media were used to cultivate B. coagulans in shake flasks. MRS (de Man, Rogosa, and Sharpe) is a nitrogen-rich medium $\left(4.0 \mathrm{~g} \cdot \mathrm{L}^{-1}\right.$ yeast extract, $8.0 \mathrm{~g} \cdot \mathrm{L}^{-1}$ meat extract, $10.0 \mathrm{~g} \cdot \mathrm{L}^{-1}$ peptone from casein, $2 \mathrm{~g} \cdot \mathrm{L}^{-1} \mathrm{~K}_{2} \mathrm{HPO}_{4}, 0.1 \mathrm{~g} \cdot \mathrm{L}^{-1} \mathrm{MgSO}_{4}, 0.03 \mathrm{~g} \cdot \mathrm{L}^{-1} \mathrm{MnSO}_{4}, 1.0 \mathrm{~g} \cdot \mathrm{L}^{-1}$ Tween-80 and $20 \mathrm{~g} \cdot \mathrm{L}^{-1}$ glucose). A reduced-nutrient medium was prepared as recommended by DSMZ $\left(3.0 \mathrm{~g} \cdot \mathrm{L}^{-1}\right.$ meat extract, $5.0 \mathrm{~g} \cdot \mathrm{L}^{-1}$ peptone from casein and $0.01 \mathrm{~g} \cdot \mathrm{L}^{-1} \mathrm{MnSO}_{4}$ ). This medium, supplemented with crude FOS, was used for FOS treatment by batch fermentation in the bioreactor system. The inoculum was grown in the same medium. A Glucose Yeast Extract Agar (GYEA) medium $\left(5.0 \mathrm{~g} \cdot \mathrm{L}^{-1}\right.$ peptone from casein, $5.0 \mathrm{~g} \cdot \mathrm{L}^{-1}$ yeast extract, $2.0 \mathrm{~g} \cdot \mathrm{L}^{-1}$ glucose, $0.5 \mathrm{~g} \cdot \mathrm{L}^{-1} \mathrm{~K}_{2} \mathrm{HPO}_{4}, 0.5 \mathrm{~g} \cdot \mathrm{L}^{-1} \mathrm{KH}_{2} \mathrm{PO}_{4}, 0.3 \mathrm{~g} \cdot \mathrm{L}^{-1} \mathrm{MgSO}_{4}, 0.01 \mathrm{~g} \cdot \mathrm{L}^{-1} \mathrm{MnSO}_{4}$, $0.01 \mathrm{~g} \cdot \mathrm{L}^{-1} \mathrm{NaCl}$, and $15 \mathrm{~g} \cdot \mathrm{L}^{-1}$ agar) was used to determine the cell and spore counts. All components were sterilized at $121^{\circ} \mathrm{C}$ for $20 \mathrm{~min}$ except for the sugar solution, which was sterilized separately.

\subsection{Cultivation of B. coagulans}

Four strains of B. coagulans were cultivated in shake flasks to investigate their growth (biomass accumulation) and sporulation rates. The pre-culture was prepared in a $100-\mathrm{mL}$ conical flask containing $10 \mathrm{~mL}$ reduced-nutrient medium. The inoculum was cultured for $14 \mathrm{~h}$ to reach the exponential phase, and $50 \mathrm{~mL}$ culture medium in a $250-\mathrm{mL}$ conical flask was then inoculated with the pre-culture. All cultivations started at an initial optical density at $600 \mathrm{~nm}\left(\mathrm{OD}_{600}\right)$ of $0.1 \pm 10 \%$. The culture was incubated in an orbital shaker (100 rpm) (Infors HT, Einsbach, Germany) at $40{ }^{\circ} \mathrm{C}$ for $48 \mathrm{~h}$. Batch fermentations for FOS purification were carried out in a 3-L bioreactor (Applikon Biotechnology, Delft, The Netherlands) at $40^{\circ} \mathrm{C}$ with aeration at $1.3 \mathrm{vvm}$ and neutralization at $\mathrm{pH} 6.8$ using $2 \mathrm{M} \mathrm{NaOH}$. We inoculated $2 \mathrm{~L}$ of the FOS-containing reduced-nutrient medium with $5 \%$ pre-culture. The $\mathrm{OD}_{600}$ was measured in triplicate by UV/Vis spectrophotometry (Eppendorf AG, Hamburg, Germany). An aliquot was diluted with physiological saline to ensure the absorbance value was $<0.5$. The cell growth was described with specific growth rate $(\mu)$ according to Equation (1), where $t_{1}$ and $t_{2}$ refer to the start and 
end of each sampling interval. The maximal value of $\mu$ during the cultivation represented the growth rate at exponential phase $\left(\mu_{\max }\right)$.

$$
\mu=\frac{\ln \frac{O D_{600, t 2}}{O D_{600, t 1}}}{t_{2}-t_{1} 0}
$$

\subsection{Determination of Sporulation Rate}

Spore staining was carried out as previously described using $1 \%$ malachite green aqueous solution as the primary stain and $0.5 \%$ safranin solution as the secondary stain [45]. The smear was observed at $1000 \times$ (oil immersion) total magnification. The sporulation rate was defined as the ratio of the number of spores $\left(N_{\text {spore }}\right)$ to the number of total viable cells $\left(N_{\text {total }}\right)$ (Equation (2)) [46]. The number of viable cells was determined in a plating assay and expressed as colony forming units (cfu). The number of spores was determined in the same manner, but the fermentation broth was heated to $75^{\circ} \mathrm{C}$ for $10 \mathrm{~min}$ before plating to kill the vegetative cells. In each case, we prepared a 10-fold dilution series from the broth and streaked $50 \mu \mathrm{L}$ of each sample on a GYEA plate. The number of colonies was counted after incubation at $40{ }^{\circ} \mathrm{C}$ for $24-48 \mathrm{~h}$. The mean average cell number in $1 \mathrm{~mL}$ was calculated using the colony numbers of two consecutive decimal dilution levels according to Equation (3), where $N$ is the mean average of the cell number in $1 \mathrm{~mL}$ undiluted sample and $10 \times$ is the dilution factor for the lowest evaluated dilution level. For example, when we used the colony numbers on the plates for $10^{6}$ and $10^{7}$-fold dilution to calculate the cell number, the lowest evaluated dilution level is $10^{6} . V$ is the volume of the sample streaked on each plate, $n_{\mathrm{x}}$ and $n_{\mathrm{x}-1}$ refer to the colony numbers on each plate, and $m_{\mathrm{x}}$ and $m_{\mathrm{x}-1}$ are the numbers of streaked plate at each dilution level.

$$
\begin{gathered}
\text { Sporulation rate }=\frac{N_{\text {spore }}}{N_{\text {total }}} \times 100 \% \\
N=\frac{10^{x}}{V} \cdot \frac{\sum n_{x}+\sum n_{x+1}}{m_{x}+0.1 m_{x+1}}
\end{gathered}
$$

\subsection{Quantitation of FOS}

The concentration of sugars in the fermentation broth was determined by high performance liquid chromatography (HPLC) using a Dionex UltiMate 3000 HPLC system (Thermo Fisher Scientific, Waltham, MA, USA) equipped with an XBridge Amide, $3.5 \mu \mathrm{m}, 4.6 \mathrm{~mm} \times 150 \mathrm{~mm}$ column (Waters $\mathrm{GmbH}$, Eschborn, Germany). The mobile phase comprised 70:30 (v:v) acetonitrile:water with a flow rate of $1 \mathrm{~mL} \cdot \mathrm{min}^{-1}$. The water fraction was supplemented with $0.2 \%(v / v)$ trimethylamine before analysis. The column was incubated at $40^{\circ} \mathrm{C}$. Before loading analysis, the cell-free sample was diluted two-fold with deionized water. Carrez solutions I and II (Carl Roth GmbH + Co. KG, Karlsruhe, Germany) were then added to the diluted sample at a ratio of 1:100 (v:v) to precipitate proteins. The protein-free sample was further diluted 50 -fold with the mobile phase used as the diluent. The diluted sample was passed through a $0.2-\mu \mathrm{m}$ nylon syringe filter (Carl Roth $\mathrm{GmbH}+\mathrm{Co} . \mathrm{KG}$, Karlsruhe, Germany) and the filtrate was sealed in an HPLC glass vial. A set of FOS standard (FUJIFILM Wako Pure Chemical Corporation, Osaka, Japan) was used to quantitatively determine the sugar concentration. The standard solution was diluted at five levels to determine the calibration curve.

\section{Results}

\subsection{Growth and Sporulation of Different Strains of B. coagulans}

The four strains of $B$. coagulans were cultivated in MRS medium with an initial glucose concentration of $20 \mathrm{~g} \cdot \mathrm{L}^{-1}$ to compare their growth rates (measured as biomass accumulation). As shown in Figure 1, B. coagulans PS5 was the fastest-growing strain, reaching the highest $\mathrm{OD}_{600}$ value of 17 after $48 \mathrm{~h}$. B. coagulans Thorne grew more slowly, but B. coagulans DSM1 and 2312 were the slowest, producing the 
least biomass during the same cultivation period. The growth and biomass accumulation correlated with substrate consumption: B. coagulans DSM2312 had utilized only $54.1 \%$ of the glucose in the medium after $24 \mathrm{~h}$, whereas $B$. coagulans PS5 had consumed all the glucose in the medium. The sporulation of the four strains were examined with the optical microscope. Figure 2 shows that none of the four strains formed spores in the MRS medium after 48-h cultivation. Moreover, no colony was observed in the determination of spore number using plating assay.

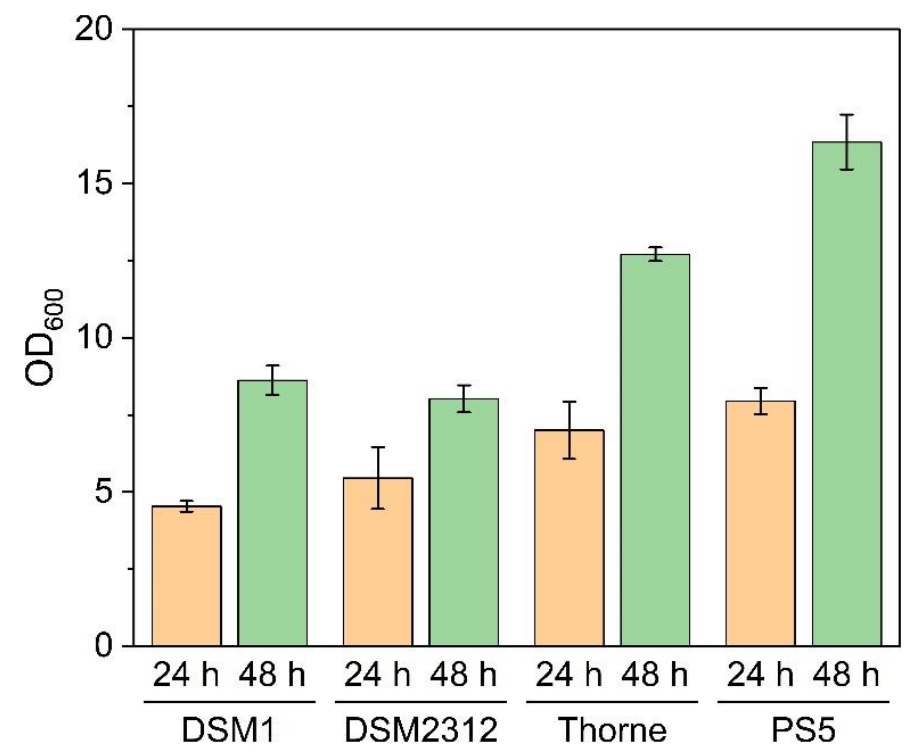

Figure 1. Accumulation of B. coagualans biomass in MRS medium (represented by $\mathrm{OD}_{600}$ values) at an incubation temperature of $40^{\circ} \mathrm{C}$ for 24 and $48 \mathrm{~h}$. Values are means \pm standard deviation of $n=$ 3 measurements.

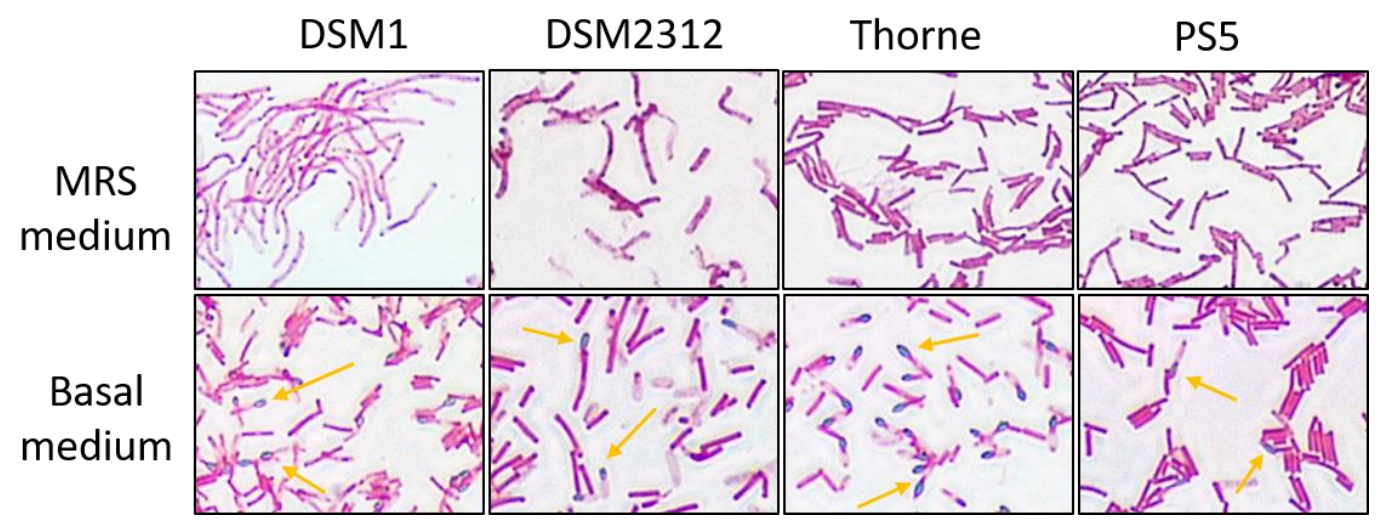

Figure 2. Morphology of B. coagulans cells (red) and endospores (green) in MRS and basal medium. The yellow arrows indicate the typical morphology of the endospores. The cells were cultivated at $40^{\circ} \mathrm{C}$ for $48 \mathrm{~h}$.

\subsection{Sporulation of B. coagulans in Basal Medium}

Since the endospore formation is usually triggered by a lack of certain nutrient or change in cultivation conditions, the sporulation of B. coagulans was investigated in basal medium, which contained only peptone, meat extract, and manganese sulfate. Given the low nitrogen content and absence of sugars, all four strains grew much more slowly than in MRS medium and lower OD 600 values were observed after 24 and $48 \mathrm{~h}$ (Figure 3). In contrast to MRS medium, where the $\mathrm{OD}_{600}$ values of all strains were higher at $48 \mathrm{~h}$ than at $24 \mathrm{~h}$, only B. coagulans Thorne continued to grow after $24 \mathrm{~h}$ and in the three other strains the $\mathrm{OD}_{600}$ declined, suggesting nutrient limitation had occurred. 


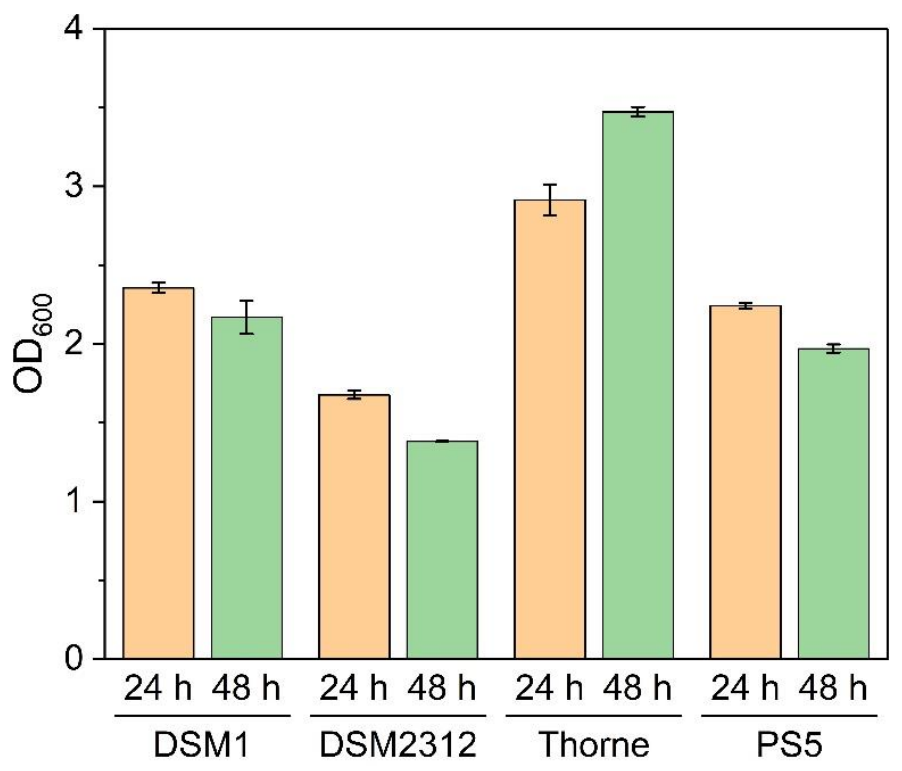

Figure 3. Accumulation of B. coagualans biomass in basal medium (represented by $\mathrm{OD}_{600}$ values) at an incubation temperature of $40^{\circ} \mathrm{C}$ for 24 and $48 \mathrm{~h}$. Values are means \pm standard deviation of $n=$ 3 measurements.

As the rate of biomass accumulation declined, the sporulation of all four B. coagulans strains was successfully induced in the basal medium in the presence of the manganese sulfate after cultivation for $48 \mathrm{~h}$ (Figure 2). However, the sporulation rate was highest for B. coagulans Thorne, followed by DSM1, DSM2312, and PS5. These results were confirmed by cell plating assays (Figure 4). The total viable cell count for B. coagulans Thorne was $7.06 \times 10^{8} \mathrm{cfu} \cdot \mathrm{mL}^{-1}$ with a sporulation rate of $19.0 \%$. The other strains had much lower numbers of vegetative cells and spores under the same conditions.

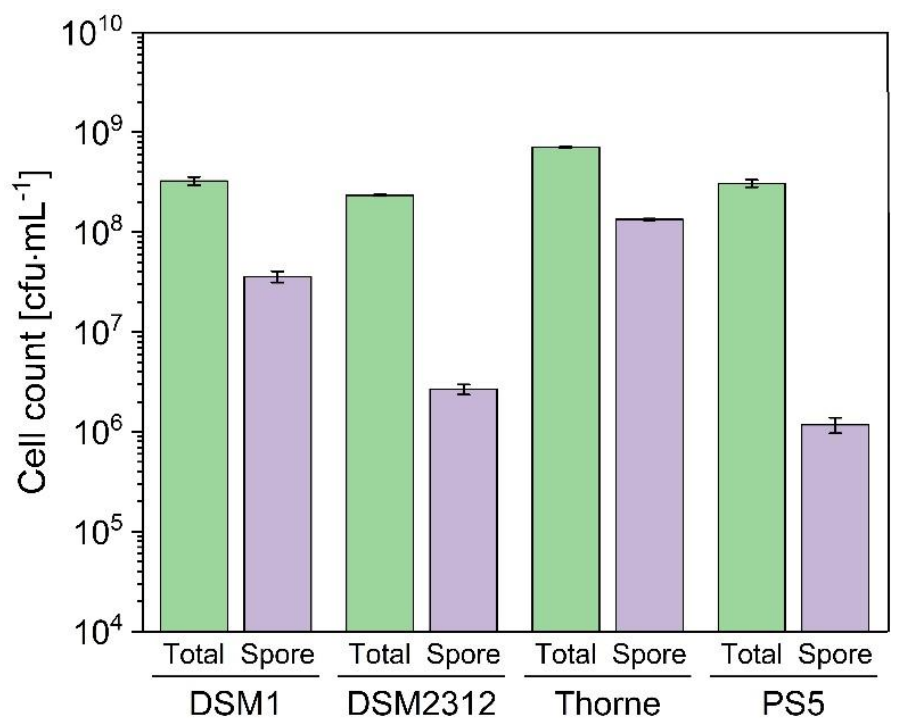

Figure 4. The number of vegetative B. coagulans cells and endospores after cultivation in basal medium at $40{ }^{\circ} \mathrm{C}$ for $48 \mathrm{~h}$. Values are means \pm error range of $n=2$ measurements.

\subsection{Fermentation of B. coagulans in the Bioreactor for the Treatment of Crude FOS}

The crude FOS solution was prepared by the enzymatic conversion of sucrose. The chromatogram (Figure 5) shows the components in the crude FOS solution, including the residual sucrose, monosaccharides as byproducts, and oligosaccharides as target products. The sugar concentrations were calculated by integrating the peak areas. Figure 6 shows the variation of each sugar component 
during the enzymatic conversion. The glucose was rapidly converted to kestose at the beginning of the reaction. The concentration of kestose reached the maximum within $60 \mathrm{~min}$, and then, gradually decreased, as the kestose was further converted to longer oligosaccharides. The chain of FOS extended while the glucose was released, leading to the increase in glucose concentration. The reaction for the production of crude FOS was terminated when the glucose concentration reached $160-180 \mathrm{~g} \cdot \mathrm{L}^{-1}$. This FOS solution was diluted before adding it to the growth medium as a carbon source in order to avoid the inhibition of cell growth caused by high sugar concentrations and consequent osmosis pressure. The final glucose concentration in the growth medium was adjusted to $20 \mathrm{~g} \cdot \mathrm{L}^{-1}$.

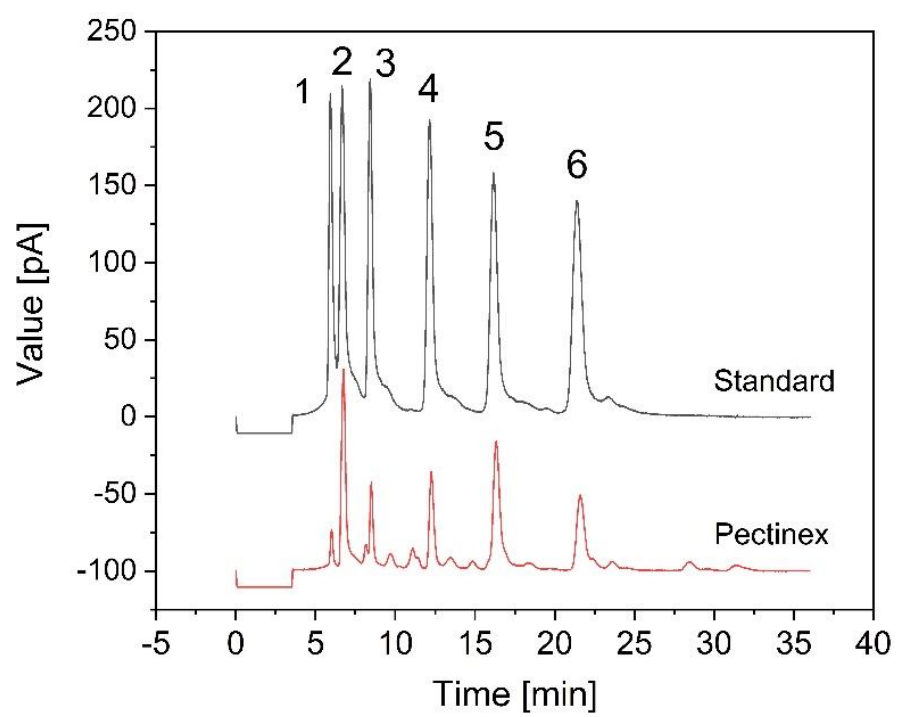

Figure 5. HPLC analysis of the crude FOS produced from sucrose by incubating with Pectinex Ultra SP-L at $55{ }^{\circ} \mathrm{C}$ overnight. The peaks correspond to: (1) fructose; (2) glucose; (3) sucrose; (4) 1-kestose; (5) nystose; and (6) 1F-fructofranosylnystose. The upper curve is the chromatogram of the standard solution. The lower curve is the chromatogram of the crude FOS preparation produced by the Pectinex Ultra SP-L.

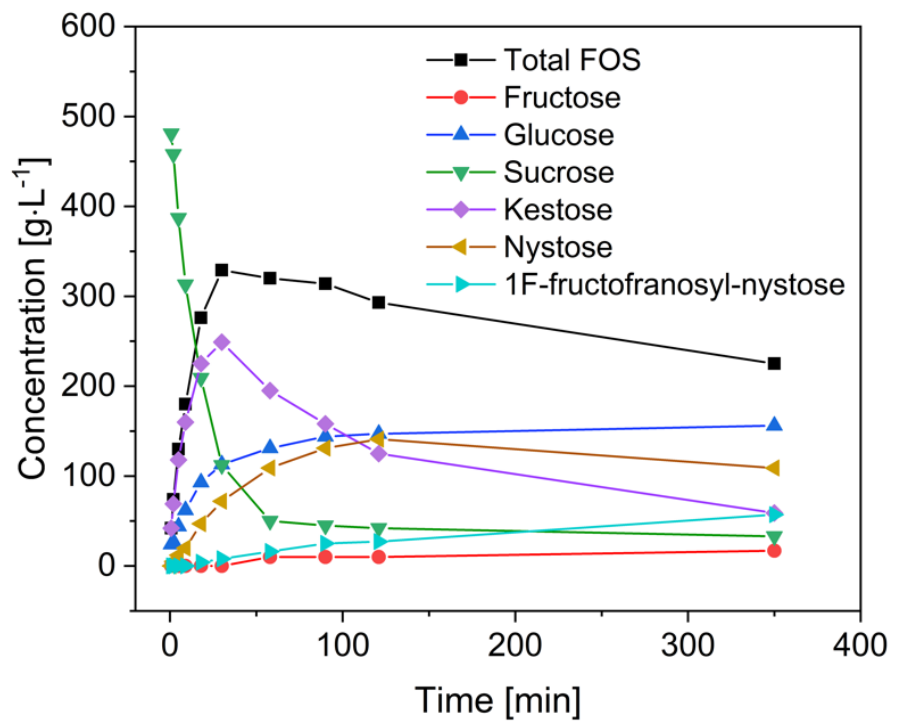

Figure 6. Time course of the FOS production from sucrose by incubating with Pectinex Ultra SP-L at $55^{\circ} \mathrm{C}$.

Figure 7 shows the growth curves of B. coagulans DSM1 and Thorne in the FOS-supplemented medium. The fermentations were carried out in the bioreactor system under the control of temperature, aeration, and $\mathrm{pH}$ values. Biomass accumulation was strongly enhanced by adding the mixed sugar 
to the bioreactor. Although both strains grew well, kinetic analysis clearly showed that B. coagulans DSM1 had a shorter lag phase and a lower $\mu_{\max }\left(0.68 \pm 0.09 \mathrm{~h}^{-1}\right)$ than $B$. coagulans Thorne $(0.99 \pm 0.06$ $\mathrm{h}^{-1}$ ) during the exponential phase. The $\mathrm{OD}_{600}$ of $B$. coagulans DSM1 steadily increased to $\sim 8.0$ and then remained steady, whereas the $\mathrm{OD}_{600}$ of $B$. coagulans Thorne declined from 8.3 to 4.7 after the growth phase. These differences were also represented by the cell counts. The total cell count for B. coagulans DSM1 decreased slightly from 6.30 to $5.94 \times 10^{8} \mathrm{cfu} \cdot \mathrm{mL}^{-1}$ during the last $24 \mathrm{~h}$ of cultivation, whereas the corresponding value for B. coagulans Thorne dropped from 4.00 to $0.99 \times 10^{9} \mathrm{cfu} \cdot \mathrm{mL}^{-1}$ (Figure 8). The increase in biomass accumulation was not directly converted to a high sporulation rate. After cultivation for $48 \mathrm{~h}$, the number of spores was 1.8 and $2.4 \times 10^{4} \mathrm{cfu} \cdot \mathrm{mL}^{-1}$ for B. coagulans DSM 1 and Thorne, respectively (Figure 8). This was much lower than the number of spores in the basal medium without sugar.

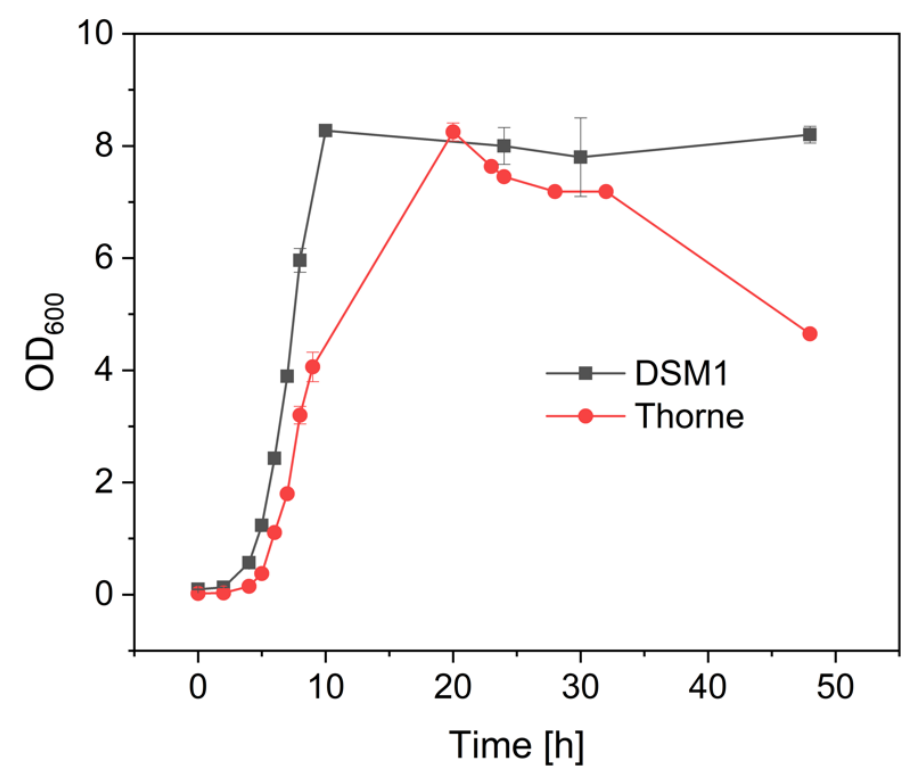

Figure 7. Growth curves of B. coagulans DSM1 and Thorne in the FOS-supplemented medium (temperature $=40^{\circ} \mathrm{C}, \mathrm{pH}=6.8$, aeration $=1.3 \mathrm{vvm}$ ). Values are means \pm standard deviation of $n=$ 3 measurements.

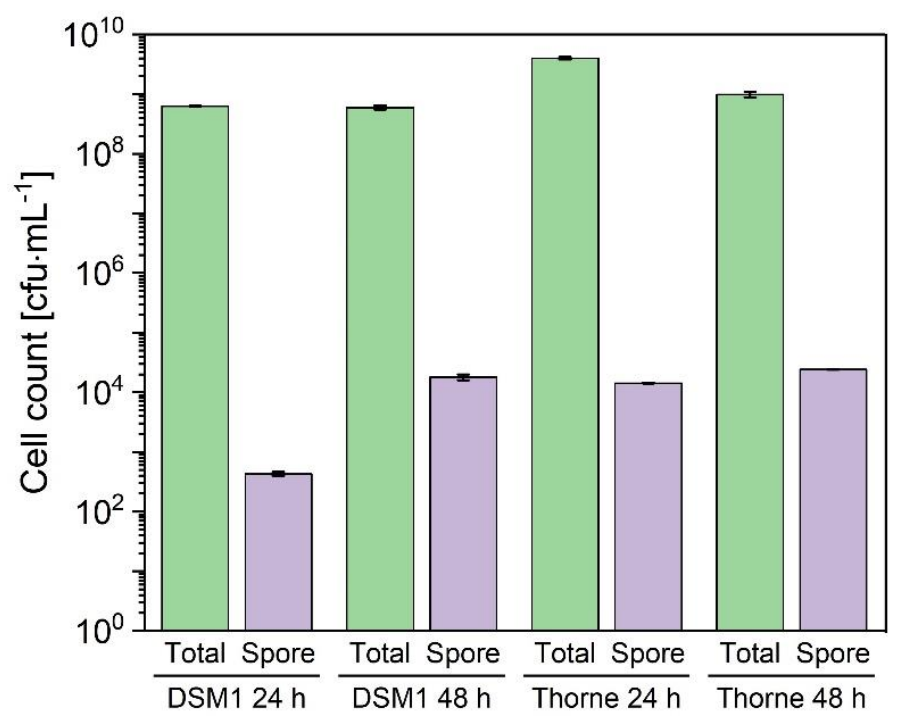

Figure 8. Total viable cell counts and spore counts of B. coagulans DSM1 and Thorne in the batch fermentation with the crude FOS preparation (temperature $=40^{\circ} \mathrm{C}, \mathrm{pH}=6.8$, aeration $=1.3 \mathrm{vvm}$ ). Values are means \pm error range of $n=2$ measurements. 
During fermentation, biomass accumulation was accompanied by substrate consumption to provide the energy and carbon necessary for cell growth. We found that the monosaccharides were preferentially utilized, as shown by the disappearance of the fructose and glucose peaks from the chromatogram after $24 \mathrm{~h}$ (Figure 9), whereas the peaks representing sucrose and FOS remained. The normalized concentrations of different sugars during the B. coagulans Thorne fermentation are shown as an example in Figure 10, indicating the change in each sugar component related to its initial level. The sugar consumption profile has two phases, the first involving the complete consumption of monosaccharides (glucose and fructose) with negligible utilization of sucrose and FOS, and the second (triggered by monosaccharide depletion) involving the consumption of sucrose as an alternative carbon source. During this second phase, the sucrose content declined to $\sim 50 \%$ of the starting value but the amount of biomass showed an unexpected decline, rather than increasing further.

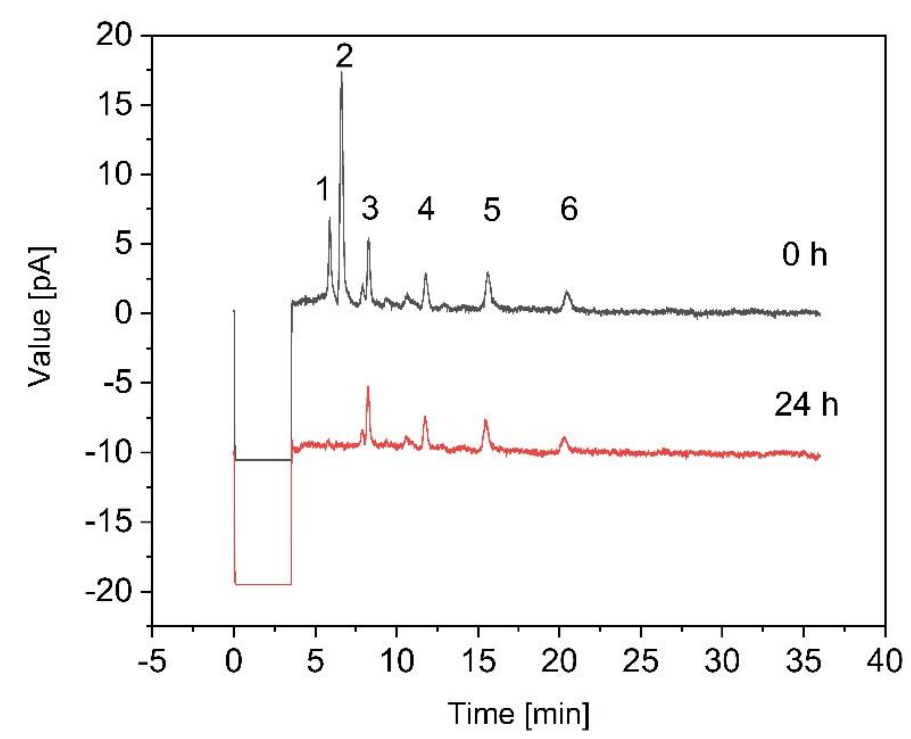

Figure 9. HPLC time course analysis of sugars in the fermentation broth of $B$. coagulans Thorne (temperature $=40^{\circ} \mathrm{C}, \mathrm{pH}=6.8$, aeration $=1.3 \mathrm{vvm}$ ). The peaks correspond to: (1) fructose; (2) glucose; (3) sucrose; (4) 1-kestose; (5) nystose; and (6) 1F-fructofranosylnystose.

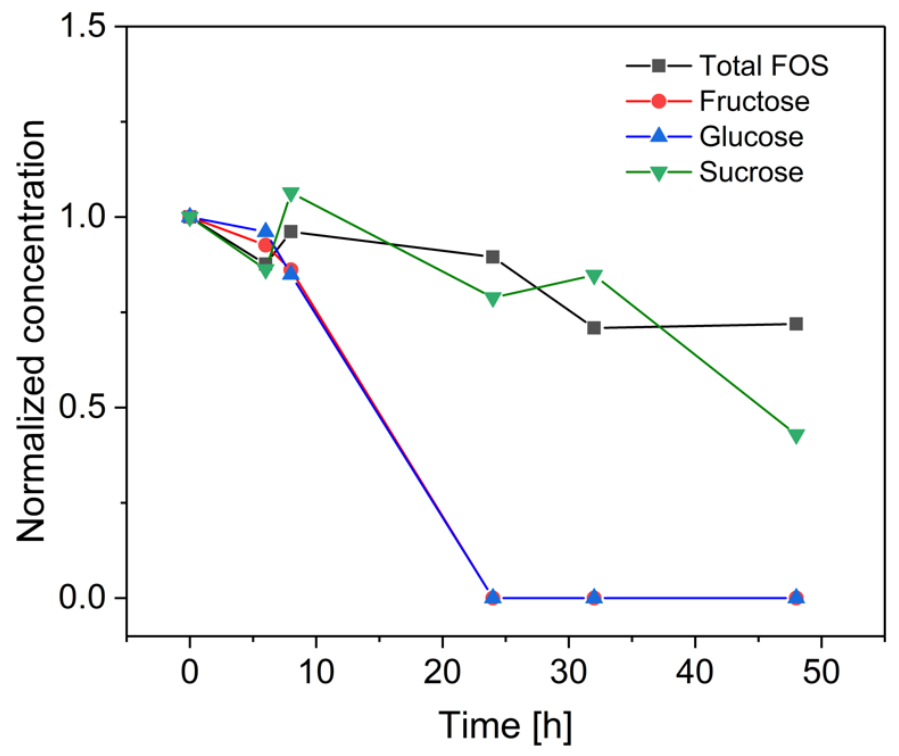

Figure 10. Consumption of sugars during the batch fermentation of B. coagulans Thorne in the bioreactor system (temperature $=40^{\circ} \mathrm{C}, \mathrm{pH}=6.8$, aeration $=1.3 \mathrm{vvm}$ ). 
Table 1 shows the selectivity of $B$. coagulans for different sugars, which in turn depends on the chain length. B. coagulans DSM1 and Thorne showed similar pattern of sugar consumption. The monosaccharides were used up prior to the consumption of sucrose and FOS. However, the sugar consumption of B. coagulans DSM1 was slightly slower than that of B. coagulans Thorne. This phenomenon corresponds to the difference in cell growth. The preference for monosaccharides ensures that few of the FOS are utilized and the residual sucrose can be converted into more FOS using a cascade process.

Table 1. Concentration of sugars in the fermentation broth during the first phase of sugar utilization.

\begin{tabular}{cccccccc}
\hline & \multicolumn{7}{c}{ Concentration $\left[\mathbf{g} \cdot \mathbf{L}^{-\mathbf{1}}\right.$ ] } \\
\hline Strain & Time & Fructose & Glucose & Sucrose & 1-Kestose & Nystose & $\mathbf{1}^{\text {F }}$-Nystose \\
\hline \multirow{3}{*}{ DSM1 } & $0 \mathrm{~h}$ & 5.4 & 25.6 & 4.4 & 4.4 & 4.5 & 3.9 \\
& $24 \mathrm{~h}$ & 0.4 & 0.6 & 3.3 & 3.6 & 3.1 & 3.7 \\
& $48 \mathrm{~h}$ & 0.0 & 0.0 & 2.6 & 3.8 & 3.5 & 3.6 \\
\hline \multirow{3}{*}{ Thorne } & $0 \mathrm{~h}$ & 6.1 & 21.2 & 5.6 & 4.0 & 6.1 & 1.9 \\
& $24 \mathrm{~h}$ & 0.0 & 0.0 & 4.4 & 3.9 & 4.9 & 2.0 \\
& $48 \mathrm{~h}$ & 0.0 & 0.0 & 2.4 & 2.7 & 3.7 & 2.2 \\
\hline
\end{tabular}

\section{Discussion}

MRS is a complex medium that is widely used to cultivate lactobacilli and $B$. coagulans for the production of lactic acid because it provides all necessary vitamins, amino acids, and growth factors [43,47]. This medium is therefore useful to determine the growth properties of different $B$. coagulans strains. Some other complex medium that contain the necessary nutrients can also be used for this purpose. For example, B. coagulans DSM1 was cultivated in glucose yeast-extract carbonate medium to achieve the maximum $\mathrm{OD}_{600}$ of $\sim 12$ [48]. High rates of growth and biomass accumulation are necessary for the production of probiotics because the biomass is the primary product, and the high growth rate can enhance the space-time yield, thus reducing the production costs. Furthermore, a fast-growing microorganism tends to be more competitive in a community, helping probiotics to inhibit the growth of pathogens. A high growth rate is also associated with the rapid consumption of glucose, which is desirable when the purpose of the bacteria is to remove glucose from a crude FOS preparation.

Sporulation is a key advantage of $B$. coagulans compared to other probiotic microorganisms because the spores can resist extreme $\mathrm{pH}$ conditions and digestive enzymes as they pass through the gastrointestinal tract [49]. However, none of the four strains formed spores in MRS medium. This suggested that nutrient-rich medium is unsuitable for the analysis of spore formation, probably because endospores are a dormant form that helps cells to survive in harsh environments and they tend not to form under mild conditions when sufficient nutrients are available [50]. A reduced-nutrient medium was therefore used to evaluate the sporulation rate of these strains. Reducing the nutrient supplement primarily caused a decline in biomass accumulation. The nutrient limitation of B. coagulans DSM1, DSM 2012, and PS5 was observed in the basal medium, suggesting that they have higher nutrient requirement than $B$. coagulans Thorne. The qualitative effects of nutrient limitation were not the same in these three strains, reflecting differences in their nutrient requirements and metabolic capacity. An ideal probiotic strain would achieve high biomass accumulation with minimal nutrient requirements because this would reduce the cost of the nutrients added to the growth medium. In addition to the better growth, B. coagulans Thorne also possesses higher productivity of endospores than the other strains. However, the cell and spore counts in this study were 10-100-fold lower than reported for other strains [42,51]. This may reflect the lack of carbohydrates and low concentration of other nutrients in basal medium, as well as differences in the experimental methods between this study and earlier reports (e.g., shake flask cultures in this study but bioreactor systems with $\mathrm{pH}$ control and regulated aeration in other studies). Nevertheless, our experimental setup was sufficient to highlight differences 
among the four strains in terms of biomass accumulation and sporulation rate. It is remarkable that B. coagulans PS5 showed the greatest deficit in biomass accumulation among the four strains when comparing basal medium to MRS medium yet also had a low sporulation rate $(<0.5 \%)$. This strain is widely used for the industrial production of lactic acid, thus the higher nutrient requirement is likely to reflect its high growth rate and productive metabolism. The capacity for sporulation may have been lost because this characteristic is not needed during the screening of highly-productive lactic acid strains, but sporulation is a desirable feature when $B$. coagulans is used as a probiotic.

B. coagulans is a versatile bacterium, which has been used in various fields, e.g., production of lactic acid, probiotic preparations, and enzymes $[47,49]$. Each application has unique requirements that can be met by different strains. Many probiotic B. coagulans strains have been isolated from diverse sources including fermented tea and vegetables [41,52,53]. It is difficult to select the most appropriate strain, although decision making can be facilitated by systematically listing the properties of each candidate. Thus far, we characterized the biological features of the four B. coagulans strains in this study by comparing nutrient requirements, growth rate, and spore-forming capacity (Table 2). $B$. coagulans Thorne was shown to possess the most suitable characteristics for the treatment of the FOS preparations and we therefore selected this strain for testing, along with the second-best candidate $B$. coagulans DSM1 as a reference.

Table 2. Characterization of B. coagulans strains to determine their suitability for the treatment of FOS preparations. The $+/-$ symbols indicate positive/negative characteristics and the number of symbols is a qualitative indicator of the relative performance in each category.

\begin{tabular}{|c|c|c|c|c|}
\hline Microbiological Feature & DSM1 & DSM2312 & Thorne & PS5 \\
\hline $\begin{array}{l}\text { Biomass accumulation } \\
\text { Biomass accumulation }^{2}\end{array}$ & + & + & ++ & +++ \\
\hline Total viable cell count ${ }^{2}$ & +++ & + & ++++ & ++ \\
\hline Spore count ${ }^{2}$ & +++ & ++ & ++++ & + \\
\hline Sporulation rate 2 & +++ & ++ & ++++ & + \\
\hline Nutrient requirements & - & -- & - & --- \\
\hline
\end{tabular}

${ }^{1}$ Related to the $\mathrm{OD}_{600}$ values in MRS medium. ${ }^{2}$ Determined in basal medium after $48 \mathrm{~h}$.

The enzymatic produced crude FOS contain not only residual sucrose and target products, but also high concentration of byproduct, i.e., glucose. The selected B. coagulans strains were cultivated in the bioreactor system to investigate the microbial treatment for the removal of this unwanted byproduct from the crude FOS. Both strains can utilize the small sugars in the crude FOS product, achieving a higher cell density than in the basal medium. However, the sporulation strongly declined in the fermentation with FOS. The low sporulation rate may reflect the presence of the sugars, which alleviated any nutritional limitations. However, the presence of glucose in the B. coagulans growth medium has previously shown no significant inhibitory effect on sporulation [42,51]. A systematic investigation of the process parameters that affect biomass accumulation and sporulation led to the development of an optimized two-stage process to improve both properties, and revealed that a lower oxygen supply promotes sporulation [42]. Considering that both growth and sporulation are highly strain-dependent, further investigation is necessary to determine the optimum culture conditions that maximize biomass accumulation and sporulation [42].

In this study, we cultivated $B$. coagulans with mixed carbon sources. The utilization of the saccharides was divided into two phases. A similar profile was observed during the production of lactic acid by B. coagulans HL-5 with a mixed sugar substrate [54]. The sucrose must be hydrolyzed by $\beta$-fructofuranosidase before utilization, and the expression of this enzyme may be inhibited in the presence of glucose. Therefore, the consumption of sucrose does not begin until the glucose is depleted. In contrast, the total FOS concentration decreased by only $28 \%$, and accordingly the proportion of FOS relative to the total sugar content increased from $26.7 \%$ to $78.3 \%$ during the fermentation. The utilization 
of FOS requires the activity of multiple operons involved in sugar metabolism or a putative fos operon which has been identified in Lactobacillus acidophilus, L. paracasei, and L. plantarum [55-57]. These operons encode a transport system that takes up FOS from the medium and the enzyme $\beta$-fructosidase, which is required for the hydrolysis of FOS. The inactivity or absence of such operons in B. coagulans may explain the limited degradation of FOS in our experiment.

Microbial treatment is an increasingly attractive solution for the purification and enrichment of oligosaccharides from a crude preparation [23,32,35,58-60]. Most previous studies involved sequential fermentation (or co-fermentation) with yeast such as S. cerevisae, K. lactis, and Pichia pastoris to remove the small sugars, increasing the purity and content of oligosaccharides. However, these previous investigations did not mention the further utilization of the biomass and the byproducts derived from the small sugars, e.g., carbon dioxide, ethanol and/or glycerol. Probiotic bacteria offer a better alternative that explores their proven health benefits and safety as food additives [39]. We are unaware of any previous studies in which probiotic microbes have been used for the treatment of FOS, possibly because many probiotic bacteria (including lactobacilli and bifidobacteria) hydrolyze and utilize short-chain oligosaccharides [56,57]. In contrast, we found that B. coagulans does not utilize FOS and is therefore ideal for the purification and enrichment of these molecules. Furthermore, the unwanted small sugars were converted into lactate, which can be recovered as the valuable byproduct lactic acid. The biomass, including the vegetative cells and endospores, can then be used as probiotics. Additional unit operations are required to recover the pure FOS from the fermentation system, but the B. coagulans-FOS mixture could also be developed as a novel synbiotic formulation for inclusion as a functional food ingredient.

\section{Conclusions}

In this study, we established an evaluation system to select the most appropriate strain for a downstream fermentation process that reduces the small sugar byproducts of a crude FOS preparation. Four B. coagulans strains were characterized in terms of their biomass accumulation, sporulation capacity, and nutrient requirements. We established an evaluation system to select the most appropriate strain for a downstream fermentation process that reduces the GI of a crude FOS preparation. B. coagulans Thorne was selected for cultivation in the bioreactor system due to its high growth rate, high sporulation rate, and low nutrient requirements. B. coagulans DSM1, which achieved the second-best performance in the evaluation system, was selected as a reference strain. Both strains preferentially utilized monosaccharides in batch fermentations, with $\mu_{\max }$ values of 0.99 and $0.68 \mathrm{~h}^{-1}$, respectively. At the end of the fermentation, the total viable cell count for $B$. coagulans Thorne was $9.9 \times 10^{8} \mathrm{cfu} \cdot \mathrm{mL}^{-1} \mathrm{compared}$ to $5.4 \times 10^{8} \mathrm{cfu} \cdot \mathrm{mL}^{-1}$ for DSM1. Furthermore, the spore count was $1.8 \times 10^{4} \mathrm{cfu} \cdot \mathrm{mL}^{-1}$ for B. coagulans Thorne and $2.4 \times 10^{4} \mathrm{cfu} \cdot \mathrm{mL}^{-1}$ for DSM1. Both strains selectively utilized the monosaccharides glucose and fructose whereas the sucrose and FOS were only metabolized to a limited extent. We have therefore proven the feasibility of a biological treatment for the purification of crude FOS using a probiotic bacterial strain. This combination of probiotic bacteria and prebiotic FOS is a new concept that can be exploited for the development of novel synbiotic formulations.

Author Contributions: R.F. carried out the experiments and analyzed the results. He wrote the manuscript and takes responsibility for the interpretation of all the data. J.P.B. developed and conducted the HPLC analysis. T.X. helped with the strain isolation and screening. P.C. led the research program and developed the experimental approach. All authors have read and agreed to the published version of the manuscript.

Funding: This research was funded by the Hessen State Ministry of Higher Education, Research and the Arts within the Hessen initiative for scientific and economic excellence (LOEWE-Program).

Acknowledgments: We would like to thank the Hessen State Ministry of Higher Education, Research and the Arts for the financial support within the Hessen initiative for scientific and economic excellence (LOEWE). Additionally, we thank ThyssenKrupp Industrial Solutions AG, Process Technologies, Bad Soden, Germany, for supplying the strain of microorganism.

Conflicts of Interest: The authors declare no conflict of interest. 


\section{Abbreviations}

$\begin{array}{ll}\text { Cfu } & \begin{array}{l}\text { colony forming unit } \\ \text { DSMZ }\end{array} \\ \text { Deutsche Sammlung von Mikroorganismen und Zellkulturen GmbH (German Collection of } \\ \text { Microorganisms and Cell Cultures) } \\ \text { high performance liquid chromatography } \\ \text { FOS } & \text { fructo-oligosaccharides } \\ \text { FTase } & \text { fructosyltransferase } \\ \text { GF }_{2} & \text { 1-kestose } \\ \text { GF }_{3} & \text { nystose } \\ \text { GF } & \text { fructofranosyl nystose } \\ \text { GI } & \text { glycemic index } \\ \text { GYEA } & \text { Glucose Yeast Extract Agar } \\ \text { OD } 600 & \text { optical density at } \lambda=600 \mathrm{~nm}\end{array}$

\section{References}

1. Kuo, S.-M. The interplay between fiber and the intestinal microbiome in the inflammatory response. Adv. Nutr. 2013, 4, 16-28. [CrossRef] [PubMed]

2. Bali, V.; Panesar, P.S.; Bera, M.B.; Panesar, R. Fructo-oligosaccharides: Production, Purification and Potential Applications. Crit. Rev. Food Sci. Nutr. 2015, 55, 1475-1490. [CrossRef] [PubMed]

3. Roberfroid, M.; Slavin, J. Nondigestible oligosaccharides. Crit. Rev. Food Sci. Nutr. 2000, 40, 461-480. [CrossRef] [PubMed]

4. Li, W.; Wang, K.; Sun, Y.; Ye, H.; Hu, B.; Zeng, X. Influences of structures of galactooligosaccharides and fructooligosaccharides on the fermentation in vitro by human intestinal microbiota. J. Funct. Foods 2015, 13, 158-168. [CrossRef]

5. Gibson, G.R.; Wang, X. Regulatory effects of bifidobacteria on the growth of other colonic bacteria. J. Appl. Bacteriol. 1994, 77, 412-420. [CrossRef] [PubMed]

6. Markowiak, P.; Śliżewska, K. Effects of Probiotics, Prebiotics, and Synbiotics on Human Health. Nutrients 2017, 9, 1021. [CrossRef]

7. Molis, C.; Flourié, B.; Ouarne, F.; Gailing, M.F.; Lartigue, S.; Guibert, A.; Bornet, F.; Galmiche, J.P. Digestion, excretion, and energy value of fructooligosaccharides in healthy humans. Am. J. Clin. Nutr. 1996, 64, 324-328. [CrossRef]

8. Yıldı, S. The Metabolism of Fructooligosaccharides and Fructooligosaccharide-Related Compounds in Plants. Food Rev. Int. 2010, 27, 16-50. [CrossRef]

9. Cummings, J.H.; Macfarlane, G.T.; Englyst, H.N. Prebiotic digestion and fermentation. Am. J. Clin. Nutr. 2001, 73, 415S-420S. [CrossRef]

10. Bornet, F.R.J.; Brouns, F.; Tashiro, Y.; Duvillier, V. Nutritional aspects of short-chain fructooligosaccharides: Natural occurrence, chemistry, physiology and health implications. Dig. Liver Dis. 2002, 34, S111-S120. [CrossRef]

11. Mutanda, T.; Mokoena, M.P.; Olaniran, A.O.; Wilhelmi, B.S.; Whiteley, C.G. Microbial enzymatic production and applications of short-chain fructooligosaccharides and inulooligosaccharides: Recent advances and current perspectives. J. Ind. Microbiol. Biotechnol. 2014, 41, 893-906. [CrossRef] [PubMed]

12. Pandey, K.R.; Naik, S.R.; Vakil, B.V. Probiotics, prebiotics and synbiotics-A review. J. Food Sci. Technol. 2015, 52, 7577-7587. [CrossRef] [PubMed]

13. Sangeetha, P.T.; Ramesh, M.N.; Prapulla, S.G. Recent trends in the microbial production, analysis and application of Fructooligosaccharides. Trends Food Sci. Technol. 2005, 16, 442-457. [CrossRef]

14. Singh, S.P.; Jadaun, J.S.; Narnoliya, L.K.; Pandey, A. Prebiotic Oligosaccharides: Special Focus on Fructooligosaccharides, Its Biosynthesis and Bioactivity. Appl. Biochem. Biotechnol. 2017, 183, 613-635. [CrossRef]

15. Campbell, J.M.; Bauer, L.L.; Fahey, G.C.; Hogarth, A.J.C.L.; Wolf, B.W.; Hunter, D.E. Selected Fructooligosaccharide (1-Kestose, Nystose, and 1 F - $\beta$-Fructofuranosylnystose) Composition of Foods and Feeds. J. Agric. Food Chem. 1997, 45, 3076-3082. [CrossRef] 
16. Vega-Paulino, R.J.; Zúniga-Hansen, M.E. Potential application of commercial enzyme preparations for industrial production of short-chain fructooligosaccharides. J. Mol. Catal. B Enzym. 2012, 76, 44-51. [CrossRef]

17. Ur Rehman, A.; Kovacs, Z.; Quitmann, H.; Ebrahimi, M.; Czermak, P. Enzymatic production of fructo-oligosaccharides from inexpensive and abundant substrates using a membrane reactor system. Sep. Sci. Technol. 2016, 58, 1537-1545. [CrossRef]

18. Ganaie, M.A.; Lateef, A.; Gupta, U.S. Enzymatic trends of fructooligosaccharides production by microorganisms. Appl. Biochem. Biotechnol. 2014, 172, 2143-2159. [CrossRef]

19. Hang, Y.D.; Woodams, E.E. Optimization of Enzymatic Production of Fructo-oligosaccharides from Sucrose. LWT 1996, 29, 578-580. [CrossRef]

20. Ghazi, I.; Fernandez-Arrojo, L.; Garcia-Arellano, H.; Ferrer, M.; Ballesteros, A.; Plou, F.J. Purification and kinetic characterization of a fructosyltransferase from Aspergillus aculeatus. J. Biotechnol. 2007, 128, $204-211$. [CrossRef]

21. Tanriseven, A.; Aslan, Y. Immobilization of Pectinex Ultra SP-L to produce fructooligosaccharides. Enzym. Microb. Technol. 2005, 36, 550-554. [CrossRef]

22. Spohner, S.C.; Czermak, P. Heterologous expression of Aspergillus terreus fructosyltransferase in Kluyveromyces lactis. New Biotechnol. 2016, 33, 473-479. [CrossRef] [PubMed]

23. Srivastava, A.; Mishra, S. Enrichment and evaluation of galacto-oligosaccharides produced by whole cell treatment of sugar reaction mixture. Mol. Biol. Rep. 2019, 46, 1181-1188. [CrossRef] [PubMed]

24. Chiasson, J.-L. Glycemic index of foods and glycemic control in type I diabetes. Curr. Opin. Endocrinol. Diabetes 2000, 7, 25-30. [CrossRef]

25. Wong, J.M.W.; Jenkins, D.J.A. Carbohydrate digestibility and metabolic effects. J. Nutr. 2007, 137, 2539S-2546S. [CrossRef]

26. Campos, D.; Mescua, L.; Aguilar-Galvez, A.; Chirinos, R.; Pedreschi, R. Effect of Yacon (Smallanthus sonchifolius) fructooligosaccharide purification technique using activated charcoal or ion exchange fixed bed column on recovery, purity and sugar content. Int. J. Food Sci. Technol. 2017, 52, 2637-2646. [CrossRef]

27. Nobre, C.; Suvarov, P.; De Weireld, G. Evaluation of commercial resins for fructo-oligosaccharide separation. New Biotechnol. 2014, 31, 55-63. [CrossRef]

28. Kuhn, R.C.; Palacio, L.; Prádanos, P.; Hernández, A.; Filho, F.M. Selection of membranes for purification of fructooligosaccharides. Desalin. Water Treat. 2011, 27, 18-24. [CrossRef]

29. Alles, M.J.L.; Tessaro, I.C.; Noreña, C.P.Z. Concentration and Purification of Yacon (Smallanthus sonchifolius) Root Fructooligosaccharides Using Membrane Technology. Food Technol. Biotechnol. 2015, 53, 190-200. [CrossRef]

30. Nobre, C.; Teixeira, J.A.; Rodrigues, L.R. Fructo-oligosaccharides purification from a fermentative broth using an activated charcoal column. New Biotechnol. 2012, 29, 395-401. [CrossRef]

31. Jong, W.Y.; Seung, K.S. The production of high-content fructo-oligosaccharides from sucrose by the mixed-enzyme system of fructosyltransferase and glucose oxidase. Biotechnol. Lett. 1993, 15, 573-576. [CrossRef]

32. Zhao, B.; Zhou, L.; Ma, L.; He, Y.; Gao, J.; Li, D.; Jiang, Y. Co-immobilization of glucose oxidase and catalase in silica inverse opals for glucose removal from commercial isomaltooligosaccharide. Int. J. Biol. Macromol. 2018, 107, 2034-2043. [CrossRef] [PubMed]

33. Yun, J.W. Fructooligosaccharides-Occurrence, preparation, and application. Enzym. Microb. Technol. 1996, 19, 107-117. [CrossRef]

34. Aslan, Y.; Tanrıseven, A. Immobilization of Pectinex Ultra SP-L to produce galactooligosaccharides. J. Mol. Catal. B Enzym. 2007, 45, 73-77. [CrossRef]

35. Nobre, C.; Castro, C.C.; Hantson, A.-L.; Teixeira, J.A.; De Weireld, G.; Rodrigues, L.R. Strategies for the production of high-content fructo-oligosaccharides through the removal of small saccharides by co-culture or successive fermentation with yeast. Carbohydr. Polym. 2016, 136, 274-281. [CrossRef] [PubMed]

36. Chauhan, D.; Patel, Y.; Doshi, J.A.; Doshi, R.D.; Bose, A. Draft Genome Sequence of Bacillus coagulans ZB29, a Commercial Probiotic Strain. Microbiol. Resour. Announc. 2019, 8, e01125-18. [CrossRef] [PubMed] 
37. Food and Agriculture Organization of the United Nations; World Health Organization. Probiotics in Food: Health and Nutritional Properties and Guidelines for Evaluation; report of a Joint FAO/WHO Expert Consultation on Evaluation of Health and Nutritional Properties of Probiotics in Food including Powder Milk with Live Lactic Acid Bacteria, report of a Joint FAO/WHO Working Group on Drafting Guidelines for the Evaluation of Probiotics in Food; FAO and WHO: Cordoba, Argentina, 2006; Available online: http://www.fao.org/3/a-a0512e.pdf (accessed on 10 September 2019).

38. Hill, C.; Guarner, F.; Reid, G.; Gibson, G.R.; Merenstein, D.J.; Pot, B.; Morelli, L.; Canani, R.B.; Flint, H.J.; Salminen, S.; et al. Expert consensus document. The International Scientific Association for Probiotics and Prebiotics consensus statement on the scope and appropriate use of the term probiotic. Nat. Rev. Gastroenterol. Hepatol. 2014, 11, 506-514. [CrossRef]

39. Aminlari, L.; Shekarforoush, S.S.; Hosseinzadeh, S.; Nazifi, S.; Sajedianfard, J.; Eskandari, M.H. Effect of Probiotics Bacillus coagulans and Lactobacillus plantarum on Lipid Profile and Feces Bacteria of Rats Fed Cholesterol-Enriched Diet. In Probiotics Antimicrobial Proteins; Springer US: New York, NY, USA, 2018. [CrossRef]

40. Monteiro, C.R.A.V.; do Carmo, M.S.; Melo, B.O.; Alves, M.S.; Dos Santos, C.I.; Monteiro, S.G.; Bomfim, M.R.Q.; Fernandes, E.S.; Monteiro-Neto, V. In Vitro Antimicrobial Activity and Probiotic Potential of Bifidobacterium and Lactobacillus against Species of Clostridium. Nutrients 2019, 11, 448. [CrossRef]

41. Feng, C.; Li, Z.; Li, K.; Zhang, M.; Wang, C.; Luo, X.; Zhang, T. Screening, Isolation, and Identification of Bacillus coagulans C2 in Pu'er Tea. In Advances in Applied Biotechnology; Zhang, T.-C., Nakajima, M., Eds.; Springer: Berlin/Heidelberg, Germany, 2015; pp. 557-562. ISBN 978-3-662-46317-8.

42. Sen, R.; Babu, K.S. Modeling and optimization of the process conditions for biomass production and sporulation of a probiotic culture. Process Biochem. 2005, 40, 2531-2538. [CrossRef]

43. Zhang, Y.; Chen, X.; Luo, J.; Qi, B.; Wan, Y. An efficient process for lactic acid production from wheat straw by a newly isolated Bacillus coagulans strain IPE22. Bioresour. Technol. 2014, 158, 396-399. [CrossRef]

44. Weese, J.S.; Martin, H. Assessment of commercial probiotic bacterial contents and label accuracy. Can. Vet. J. 2011, 52, 43-46. [PubMed]

45. Hussey, M.A.; Zayaitz, A. Endospore Stain Protocol. In Laboratory Protocol; American Society for Microbiology: Washington, DC, USA, 2007; Available online: http://www.asmscience.org/content/education/protocol/ protocol.3112 (accessed on 10 May 2019).

46. Bast, E. Mikrobiologische Methoden. Eine Einführung in Grundlegende Arbeitstechniken, 2nd ed.; Spektrum Akad.-Verl.: Heidelberg, Germany, 2010; ISBN 978-3-8274-1072-6.

47. Fan, R.; Ebrahimi, M.; Czermak, P. Anaerobic Membrane Bioreactor for Continuous Lactic Acid Fermentation. Membranes 2017, 7, 26. [CrossRef] [PubMed]

48. Sun, L.; Zhang, C.; Lyu, P.; Wang, Y.; Wang, L.; Yu, B. Contributory roles of two l-lactate dehydrogenases for 1-lactic acid production in thermotolerant Bacillus coagulans. Sci. Rep. 2016, 6, 37916. [CrossRef] [PubMed]

49. Konuray, G.; Erginkaya, Z. Potential Use of Bacillus coagulans in the Food Industry. Foods 2018, 7, 92. [CrossRef] [PubMed]

50. Das, S.; Sen, R. Kinetic modeling of sporulation and product formation in stationary phase by Bacillus coagulans RK-02 vis-à-vis other Bacilli. Bioresour. Technol. 2011, 102, 9659-9667. [CrossRef] [PubMed]

51. Pandey, K.R.; Vakil, B.V. Development of bioprocess for high density cultivation yield the probiotic Bacillus coagulans and its spores. J. BioSci. Biotechnol. 2016, 5, 173-181.

52. Xiong, T.; Song, S.; Huang, X.; Feng, C.; Liu, G.; Huang, J.; Xie, M. Screening and identification of functional Lactobacillus specific for vegetable fermentation. J. Food Sci. 2013, 78, M84-M89. [CrossRef]

53. Xiong, T.; Chen, J.; Huang, T.; Xie, M.; Xiao, Y.; Liu, C.; Peng, Z. Fast evaluation by quantitative PCR of microbial diversity and safety of Chinese Paocai inoculated with Lactobacillus plantarum NCU116 as the culture starter. LWT 2019, 101, 201-206. [CrossRef]

54. Lv, X.; Yu, B.; Tian, X.; Chen, Y.; Wang, Z.; Zhuang, Y.; Wang, Y. Effect of pH, glucoamylase, pullulanase and invertase addition on the degradation of residual sugar in L-lactic acid fermentation by Bacillus coagulans HL-5 with corn flour hydrolysate. J. Taiwan Inst. Chem. Eng. 2016, 61, 124-131. [CrossRef]

55. Goh, Y.J.; Lee, J.-H.; Hutkins, R.W. Functional analysis of the fructooligosaccharide utilization operon in Lactobacillus paracasei 1195. Appl. Environ. Microbiol. 2007, 73, 5716-5724. [CrossRef] 
56. Barrangou, R.; Altermann, E.; Hutkins, R.; Cano, R.; Klaenhammer, T.R. Functional and comparative genomic analyses of an operon involved in fructooligosaccharide utilization by Lactobacillus acidophilus. Proc. Natl. Acad. Sci. USA 2003, 100, 8957-8962. [CrossRef] [PubMed]

57. Buntin, N.; Hongpattarakere, T.; Ritari, J.; Douillard, F.P.; Paulin, L.; Boeren, S.; Shetty, S.A.; de Vos, W.M. An Inducible Operon Is Involved in Inulin Utilization in Lactobacillus plantarum Strains, as Revealed by Comparative Proteogenomics and Metabolic Profiling. Appl. Environ. Microbiol. 2017, 83, e02402-e02416. [CrossRef] [PubMed]

58. Castro, C.C.; Nobre, C.; De Weireld, G.; Hantson, A.-L. Microbial co-culturing strategies for fructo-oligosaccharide production. New Biotechnol. 2019, 51, 1-7. [CrossRef] [PubMed]

59. Nobre, C.; Gonçalves, D.A.; Teixeira, J.A.; Rodrigues, L.R. One-step co-culture fermentation strategy to produce high-content fructo-oligosaccharides. Carbohydr. Polym. 2018, 201, 31-38. [CrossRef] [PubMed]

60. Yang, Y.-L.; Wang, J.-H.; Teng, D.; Zhang, F. Preparation of high-purity fructo-oligosaccharides by Aspergillus japonicus beta-fructofuranosidase and successive cultivation with yeast. J. Agric. Food Chem. 2008, 56, 2805-2809. [CrossRef] [PubMed]

(C) 2020 by the authors. Licensee MDPI, Basel, Switzerland. This article is an open access article distributed under the terms and conditions of the Creative Commons Attribution (CC BY) license (http://creativecommons.org/licenses/by/4.0/). 